\title{
Issues of wind mode visualization and pedestrian comfort assessment when designing residential buildings on sloping territories in the Arctic zone
}

\author{
Ilya $V$. Dunichkin ${ }^{1,2, *}$, Emanuele Naboni $^{3}$, Anna E. Korobeinikova ${ }^{2}$ and Olga I. Poddaeva ${ }^{1}$
}

\begin{abstract}
${ }^{1}$ Educational, scientific and industrial laboratory for aerodynamic and aeroacoustic tests of building structures, Moscow State University of Civil Engineering (National Research University), Russia

${ }^{2}$ Urban planning Department, Moscow State University of Civil Engineering (National Research University), Russia

${ }^{3}$ Institute of Technology, School of Architecture, Royal Danish Academy of Fine Arts, Copenhagen, Denmark
\end{abstract}

\begin{abstract}
Subject of research: visualization of the wind regime of residential buildings on the slope area in the Arctic. Goals: the purpose of the study is to identify the problems of visualization of the wind regime on the slopes and the analysis of patterns of airflow around the sloping territories, affecting the comfort of pedestrians. Materials and methods: airflow patterns of slope areas with different characteristics and comfort assessment for humans are analyzed in the course of work. Geotechnical methods are presented in solving the problems of wind erosion and the stability of hillsides and complex terrain within the city limits. Results: The importance and novelty of the research in studying the relationship of slope geometry and environmental quality, as a decrease in comfort inevitably leads to a decrease in the development of nearby urban areas in settlements on the coast of the Arctic Ocean, problems with climate and local climate, as well as a decrease in the quality of life of people. The article considers the relationship of plastic relief with the aeration regime of the territory, the dependence of aerodynamic roughness on their height, features of aeration of the slope and hilly terrain, factors affecting the direction and speed of the wind and methods for studying the aeration regime of slope areas. Findings: The possibilities of applying existing approaches to research and visualization for slope areas are demonstrated. The direction of development of the technique for visualization of slope areas has been determined.
\end{abstract}

\footnotetext{
*Corresponding author: ecse@bk.ru
} 


\section{Introduction}

Wind mode of buildings is one of the most important criteria for the comfort of a residential area, especially in conditions of sub-zero temperatures in winter. The quality of the environment of pedestrian paths and landscaping sites is greatly influenced by the architectural and planning organization of development and relief. Therefore, it is important to carry out a qualitative study based on a wind mode visualization before making design decisions. Naboni, E. said that this is particularly true in a design that is paying attention to to assess the comfort of pedestrians both the streets and in the courtyards [1]. It should be noted that most studies on thermal and visual comfort consider objects in hot and temperate climates, so it is important to determine the research methods and the planned type of results, taking into account the conditions of the cold climate.

The cities practically did not face the problems of mastering of complex reliefs until recently, as they had sufficient areas of free reserve areas. Up to date, architects and city planners have paid attention to the development of so-called inconvenient land, which include slope areas. Residential development in the port cities of the Arctic often has accommodation in slope areas. This is due to the fact that areas with flat terrain are used for port infrastructure, logistics and industrial facilities. Residential areas on the coast of the Arctic Ocean are usually located at a distance of a sanitary protection zone from the port, which forces them to develop in sloping areas. Such a situation takes place, for example, in Murmansk, both in the existing building facing the port and in new areas nearby the ports and shipyards of the Kola Peninsula of Russia that are under construction. The design of residential buildings on slope areas is necessary for the qualitative development of these strategic areas [9]. The design needs to be parametric, thus account for a comparison of multiple options, to account for the specific climatic features of the site, in the form of subzero temperatures, high humidity, icing of structures and large snow loads. All these factors depend on the wind regime and with a significant effect reduce the comfort of pedestrians and also pose a risk to human health due to the risk of frostbite [7].

In the framework of pre-project analysis, must be determined morphological and geometrical characteristics, as they will affect, fig. 1. It is necessary to choose flat, not steep, slopes in order to avoid the formation of leeward rotor and dynamic upstream, or to take measures for local relief changes in the process of geoplasty. This issue should be given special attention as the increased wind and vortex flows inevitably affect the microclimate and the local climate of the territory and as a consequence the comfort of being in this area, especially in regions with high humidity. At the same time, the building should have the correct aeration and be ventilated.

In addition to taking into account the morphology of the slope, affecting the wind regime in the process of studying and preparing the territory of the analysis, it is necessary to realize that the development of urbanized countryside will make significant changes in the local climate. Therefore, the designer should pay special attention to determining the shape, orientation and height of the building, taking into account all the climatic features of the region, as well as other equally important features. Moreover, Poddaeva, O., Churin, P., \& Dunichkin, I. argue that the wind speed will be affected by the roughness of the underlying surface, which in the conditions of development of slope surfaces is an interesting task requiring a more detailed study of aerodynamics and wind protection of slopes and with potential urban development [14]. The need to take into account these factors and the features of the aeration regime of slopes associated with their geometric parameters pose a difficult 
task for urban planners and designers to develop the slope areas, taking into account bioclimatic comfort.
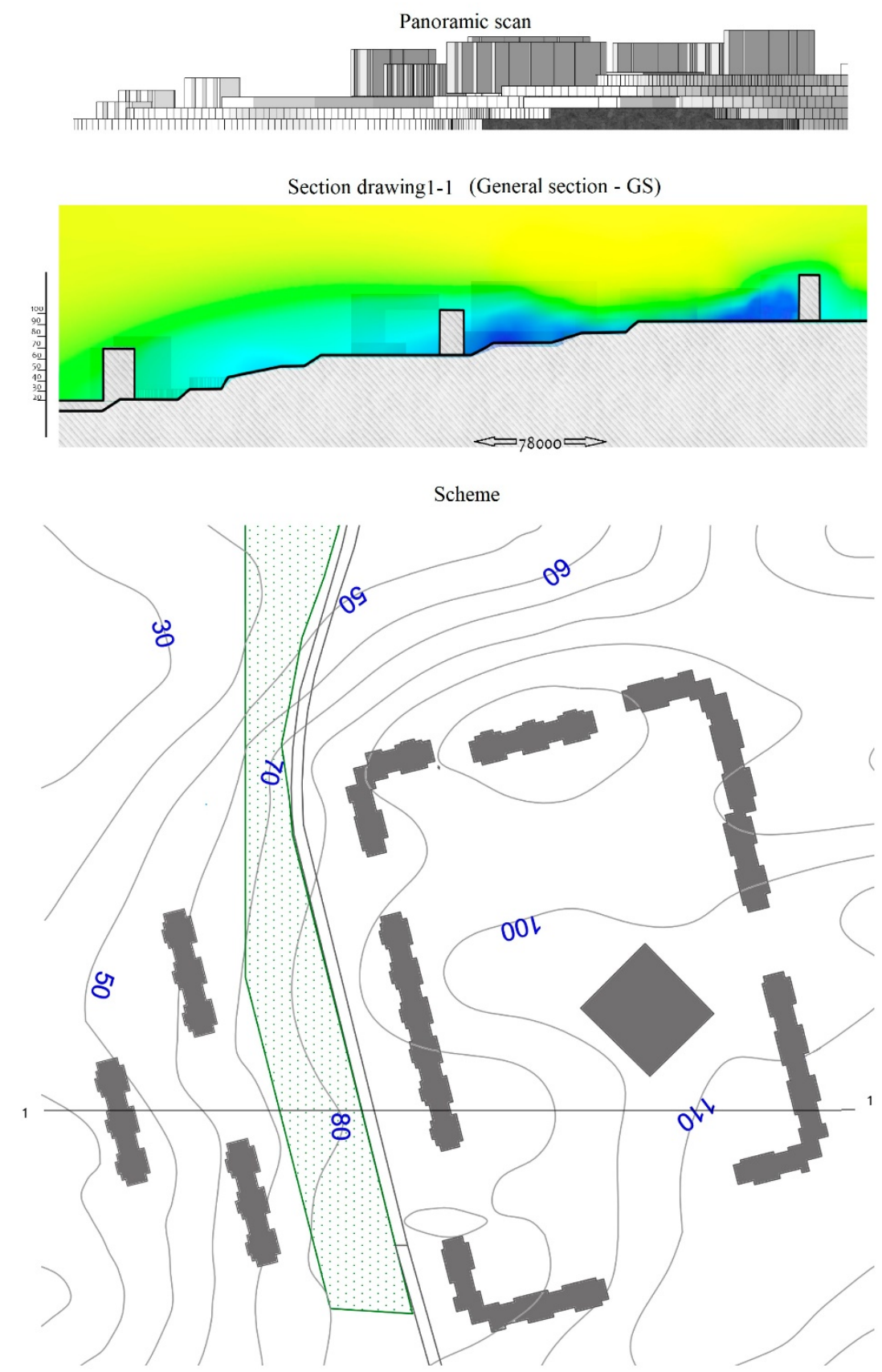

Fig. 1. Scheme, section drawing and panoramic scan of the layout of buildings on the slope area for the subsequent visualization of wind flows (Option 1). 


\section{Materials and methods}

The study of the wind flow around the slope is very important both at the stage of pre-design analysis and in the design process. On the basis of the obtained regularities and quantitative characteristics of this process, recommendations are developed to improve the aeration regime in this territory by architectural, construction and engineering methods [1]. Determining the aerodynamic characteristics of the slope is possible by several methods the method of full-scale laboratory studies, theoretical calculations, as well as methods for experimental and numerical simulation of wind effects

It is necessary to use the wind mode visualization in high-quality parametric design to solve the problem of the development of residential development on the slope areas in the Arctic [5]. The implementation requires solving the problem of drawing up a visualization of the wind regime on the masterplan of residential buildings, which is that the flow distribution fields must be parallel to the slope surface at the height of 2 meters or be horizontal and terraced with a step that allows one to get a reliable picture for evaluating comfort. Thus, there is a technical task to visualize the wind regime in sloping areas. This is a critical analysis since buildings, structures and green spaces can modify the speed and direction of air flow and, consequently, the nature of snow positions in winter. The initial approach involves the allocation of flat sections of the slope and terraces for consideration of their wind regime in numerical simulation and on physical tests in a wind tunnel [13]. This facilitates the visualization of the wind regime of the slope area. To solve the problems of pedestrian comfort assessment in the study, the method of physical testing of the location of snow deposits in the wind and the method of photo fixation of snow deposits on the model in the wind tunnel with subsequent digital processing to visualize the plan of distribution of snow deposits in height were applied.

For example, consider the project of residential development of the Kola Peninsula in the Arctic zone of the Russian Federation. Within the framework of the study, CFD-modeling of wind flows was carried out in order to identify areas that are uncomfortable for pedestrian safety [4]. The issue of visualization arose during the numerical CFD-modeling to identify comfort in terms of aeration of local areas. There was a task to investigate a wind mode. The problem of obtaining results consisted in that at reception of the map of speeds in the inclined territory where buildings are located at different levels, and it is necessary to receive data at the level of growth of the pedestrian to receive a field of speeds one plane it is not possible. In the case of the study of the development project for the Kola Peninsula were to be taken three horizontal planes for each group of houses at different levels of the slope, fig. 2. Also, for the accuracy of the data it was necessary to use vertical velocity fields. This method is longer in comparison with the study of development on flat terrain, but in this case, we see a direct relationship between the complexity of regulation and evaluation of aeration regime on the slope and its modeling. 


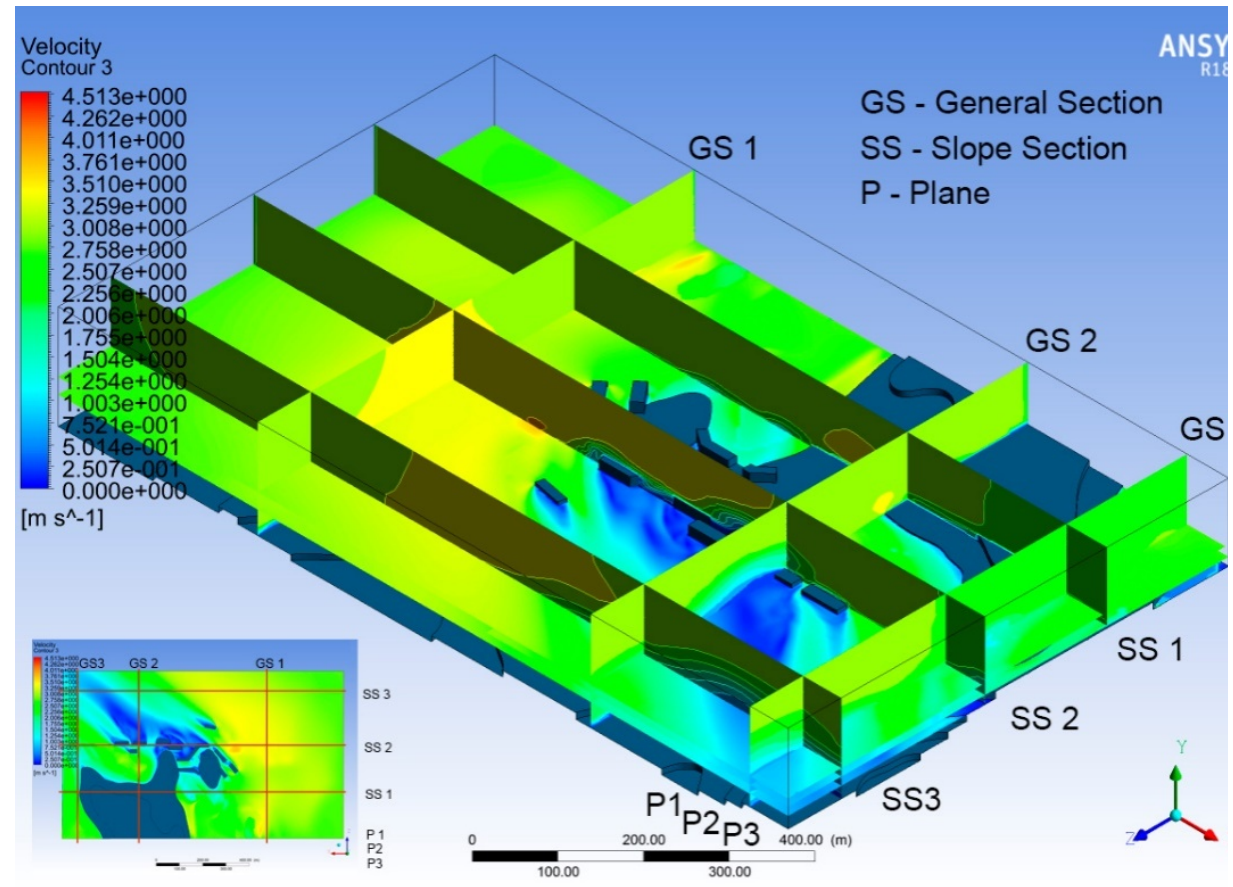

Fig. 2. 3D model of the method of visualization of the slope using two-dimensional planes, taking into account the parameters of the relief (Option 2).

\section{Analysis and results}

Parametric design of micro-districts in severe weather conditions, such as those prevailing in cold climatic zones, is one of the most critical tasks requiring a complex solution with BIMtechnologies [10]. A multifactor analysis for determining the initial environmental parameters, which includes climatic analysis of the seasons, is required to develop a comprehensive solution of parametric design, taking into account the features of cold climatic zones according to the following parameters:

Average monthly and maximum wind speeds;

Average monthly and extreme air temperatures;

The most repetitive wind directions for a month;

The amount and state of aggregation of precipitation per month.

Cold climatic zones include the polar type of climate (arctic zones) and subpolar climate. In winter, temperatures can drop to $-50^{\circ} \mathrm{C}$ due to the influence of arctic air masses, so winters are long and cold here, with lots of snow and significant snow transport in buildings.

The complex analysis includes the presence and influence of landscaping, orientation of the development of the neighborhood unit and the type of its composition [11]. Building parameters allow classifying the air permeability with the calculation of the perimeter density of the neighborhood unit (the long perimeter of the neighborhood unit to the sum of the lengths of the external facades) and the influence coefficient parameters and position of the slope relative to the building. Classification of permeability to air allows one to pre-determine the approximate ranges of the parameters of building and its location relative to the slopes. This makes possible the modeling of aeration, multivariate analysis and comparative analysis 
of a limited number of options for design solutions of construction, which reduces the work on the visualization of air flow and the time for evaluating the results by an average of 2-3 times.

The results of experimental studies allow one to determine the arrangements for the placement of a set of small architectural forms and various snow protection structures. Experimental studies conducted at the Aerodynamic and Aero Acoustic Testing of Building Structures at the Scientific and Production Laboratory of the National Research University MGSU indicate how snow transfer phenomena occur in the microdistrict territory, fig. 1, [2]. A verified simulation is carried out on the basis of physical experiments and the parameters of the development environment are determined for parametric design and optimization of design solutions in computer-aided design [12].

The method of assessing pedestrian comfort initially requires the allocation in the neighborhoods of building groups for visualization in different sections (Fig. 2) of wind speed, streamlines of air masses (Fig. 3), height of snow deposits in buildings and on a slope (Fig. 3 b).

These visualizations make it possible to adopt decisions on the optimization of the road network, the placement of landscaping, fences and small architectural forms, which can change the pedestrian comfort indicators for the better [6].

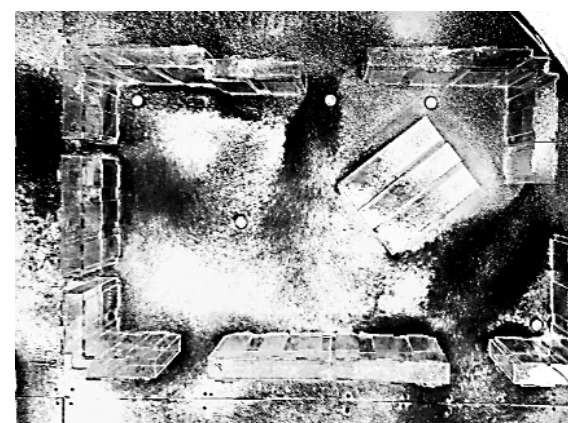

a)

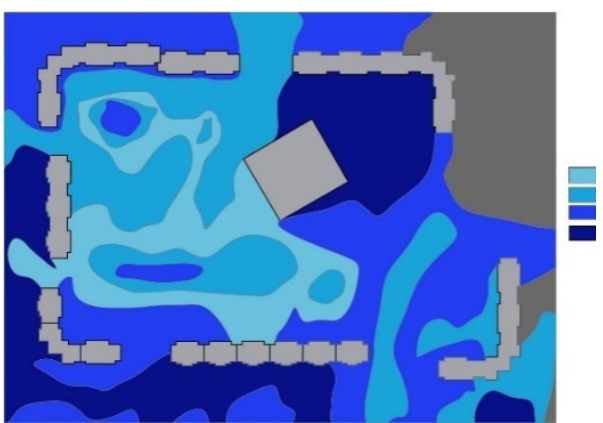

b)

Fig. 3. Photo fixation of a residential development layout on a terrace of a slope in a wind tunnel after a snow transfer test and snow drifts plan (Option 1).

\section{Conclusions}

It is important to note that the regulation of the aeration regime can be carried out by placing small architectural forms on the adjacent territory that also fulfill recreational functions in addition to the methods of geoplastics. Such a decision is rational for the organization of bioclimatic comfort in the construction of Northern cities, in which the creation of an artificial relief can be difficult because of severe climatic factors.

Thus, the study presents the possibility of developing design solutions for sloping areas that take into account the aeration regime and the dangerous effect of wind erosion, as well as the application possibilities for fixing slopes of geotechnical structures with biopositive structures affecting the parameters of aeration and the bioclimatic comfort of the environment, and hence the health indicators of the population. The development of the considered direction consists in integration of calculations of geotechnical structures and wind conditions of slope territories into the environment of complex parametric design with 
parallel modeling of engineering, geotechnical and socio-functional landscape systems that will allow to reach a qualitatively new level of design solutions [8]. Visualizations for assessing pedestrian comfort include a minimum of an additional six vertical sections and three horizontal section-plans on the slope for a complete picture, taking into account the relief considered.

It is possible to model and visualize the influence of small architectural forms and landscaping on the forms and types of snow deposits by conducting experimental studies [3]. Given the lack of existing standards for accounting snow transfer it is necessary to carry out simulation, physical testing, verification, visualization of the wind regime and snow transfer in the pedestrian zone [15]. Zones of snow deposits with visualization, located on motorways, pedestrian paths, landscaping sites, show places needed for snow protection and are the visualization basis for placing additional fences, landscaping and small architectural forms. These studies should refer to the terraces and flat slopes, and should then be conducted above surfaces with significant slope. This requires matching the areas of the visualization zones, which entails additional research and analysis of the wind regime in places where the slopes of the terrain change.

\section{References}

1. Naboni, E. (2014, December). Integration of outdoor thermal and visual comfort in parametric design. In 30th International PLEA Conference (pp. 1-10)

2. Dolganov, A., \& Kagan, P. (2018). On the design of high-rise buildings with a specified level of reliability. In E3S Web of Conferences (Vol. 33, p. 02061). EDP Sciences

3. Vigier, T., Siret, D., Moreau, G., \& Lescop, L. (2013, August). Sensitive suggestion and perception of climatic effects in virtual urban environments. In Proceedings of the ACM Symposium on Applied Perception (pp. 139-139). ACM

4. Dunichkin, I. V., Poddaeva, O. I., \& Golokhvast, K. S. Studies and evaluation of bioclimatic comfort of residential areas for improving the quality of environment. In Building Simulation (pp. 1-6). Tsinghua University Press

5. Pham, T., Musy, M., Siret, D., \& Teller, J. (2007). Methodology for integrating and analyzing environmental and urban data in 3D GIS. In Proc. of 10th AGILE International Conference on Geographic Information Science

6. Blocken, B., Stathopoulos, T., \& Van Beeck, J. P. A. J. (2016). Pedestrian-level wind conditions around buildings: Review of wind-tunnel and CFD techniques and their accuracy for wind comfort assessment. Building and Environment, 100, 50-81

7. Valger S., Fedorov A., \& Fedorova N. (2013). Simulation of incompressible turbulent flows in the vicinity of low-flow bodies using PC ANSYS Fluent.. Computingtechnology, 18(5). 27-40

8. Cherkina, V., Shushunova, N., \& Zubkova, J. (2018). Application of BIM-technologies in tasks of quality management and labour safety. In MATEC Web of Conferences (Vol. 251, p. 06004). EDP Sciences

9. Korol, O., Shushunova, N., Lopatkin, D., Zanin, A., \& Shushunova, T. (2018). Application of High-tech Solutions in Ecodevelopment. In MATEC Web of Conferences (Vol. 251, p. 06002). EDP Sciences

10. Poddaeva, O., Dunichkin, I., \& Gribach, J. (2018, June). Conducting calculating and experimental researches of the bioclimatic comfort of the residential area territory. 
In IOP Conference Series: Materials Science and Engineering (Vol. 365, No. 2, p. 022029). IOP Publishing

11. Kagan, P. (2018). Monitoring of the development of urban areas with the use of information technology. In MATEC Web of Conferences (Vol. 193, p. 05031). EDP Sciences

12. Billen, R., Cutting-Decelle, A. F., Marina, O., De Almeida, J. P., Caglioni, M., Falquet, G., ... \& Rabino, G. (2014). 3D City Models and urban information: Current issues and perspectives-European COST Action TU0801

13. Miguet, F. (2007). A further step in environment and bioclimatic analysis: the software tool Solene. IBPSA 2007, 3-6

14. Poddaeva, O., Churin, P., \& Dunichkin, I. (2016). Experimental study of wind loads on unique buildings and structures in Russia. In MATEC Web of Conferences (Vol. 86, p. 02012). EDP Sciences

15. Antoniou, N., Montazeri, H., Wigo, H., Neophytou, M. K. A., Blocken, B., \& Sandberg, M. (2017). CFD and wind-tunnel analysis of outdoor ventilation in a real compact heterogeneous urban area: Evaluation using "air delay". Building and Environment, 126, $355-372$ 